Published in final edited form as:

Depress Anxiety. 2011 October 3; 28(10): 876-884. doi:10.1002/da.20861.

\title{
Comorbidity in Hoarding Disorder
}

\author{
Randy O. Frost ${ }^{1}$, Gail Steketee ${ }^{2}$, and David F. Tolin ${ }^{3}$ \\ ${ }^{1}$ Smith College, Yale University School of Medicine \\ ${ }^{2}$ Boston University, Yale University School of Medicine \\ ${ }^{3}$ Institute of Living and Yale University School of Medicine
}

\begin{abstract}
Hoarding Disorder (HD) is currently under consideration for inclusion as a distinct disorder in DSM-5 (1). Few studies have examined comorbidity patterns in people who hoard, and the ones that have suffer from serious methodological shortcomings including drawing from populations already diagnosed with obsessive compulsive disorder (OCD), using outdated definitions of hoarding, and relying on inadequate assessments of hoarding. The present study is the first largescale study ( $\mathrm{n}=217)$ of comorbidity in a sample of people meeting recently proposed criteria for hoarding disorder (1) and relying on validated assessment procedures. The HD sample was compared to 96 participants meeting criteria for OCD without HD. High comorbidity rates were observed for major depressive disorder (MDD) as well as acquisition-related impulse control disorders (compulsive buying, kleptomania, and acquiring free things). Fewer than 20\% of HD participants met criteria for OCD, and the rate of OCD in HD was higher for men than women. Rates of MDD and acquisition-related impulse control disorders were higher among HD than OCD participants. No specific anxiety disorder was more frequent in HD, but social phobia was more frequent among men with HD than among men with OCD. Inattentive ADHD was diagnosed in $28 \%$ of HD participants and was significantly more frequent than among OCD participants (3\%). These findings form important base rates for developing research and treatments for hoarding disorder.
\end{abstract}

\section{Keywords}

compulsive hoarding; clutter; saving; difficulty discarding; psychiatric diagnosis

A recent review commissioned by the DSM-5 Anxiety, Obsessive-compulsive Spectrum, Post-traumatic, and Dissociative Disorders Work Group recommended the addition of Hoarding Disorder (HD) as a separate diagnostic entity (1). Hoarding is characterized by excessive acquisition of and difficulty discarding possessions, resulting in severely cluttered living spaces (2). It has a high prevalence rate of $2-5 \%(3-5)$, and the resulting cluttered home environment can lead to health code violations, eviction, fire, family strain, significant cost to the community, and even death (6).

Because hoarding has previously been considered a subtype of OCD, much of the research on hoarding has used samples drawn from patients seeking treatment at OCD specialty clinics. However, reviews of accumulating evidence have led to conclusions that the two are distinct disorders $(1,7)$. Since most large sample studies are of hoarding within the context of OCD, our understanding of the diagnostic placement and comorbidity of hoarding is

Corresponding Author: Randy O. Frost, Department of Psychology, Smith College, Northampton, MA 01063, rfrost@ smith.edu, Ph: (413) 585-3911, Fax: (413) 585-3986. 
limited. To underscore this concern, in the few studies in which participants were solicited for hoarding rather than OCD symptoms, non-hoarding OCD was diagnosed in only a small number of cases (5). Because of the small number of cases in these studies, the prevalence of OCD in people with hoarding disorder is not yet clear.

An additional limitation in the research on hoarding is the reliance on inadequate definitions and measures of the construct (8). Not surprisingly, the variability in assessment has resulted in wide variability in reported comorbidities. Several studies failed to find increased risk for any axis I disorder in OCD patients who reported hoarding $(11,12)$, while the majority of studies have shown increased comorbidity for selected disorders.

Recent advances in definition (1) and measurement $(9,10)$ provide the ability to more reliably diagnose and assess comorbidity in HD; however, studies using these improved assessment strategies have used small samples. The majority of studies of hoarding comorbidity have reported very high rates of depression, often significantly greater than among OCD comparison groups (13-21). Hoarding behaviors have been observed in anxiety disorders other than OCD, especially generalized anxiety disorder (GAD) and social phobia (22). Among hoarding patients with OCD, rates of these disorders have exceeded nonhoarding OCD in some studies $(16,18,19,23)$, while the opposite pattern has been found in studies of patients solicited for hoarding and not OCD $(13,20)$. Interestingly, Pertusa et al. (17) reported higher rates of GAD in OCD cases (with or without hoarding) compared to HD cases without OCD, whereas higher rates of social phobia occurred in all $\mathrm{HD}$ cases, regardless of accompanying OCD. That is, GAD seemed more strongly associated with OCD, whereas social phobia was more strongly associated with hoarding. Despite apparently elevated rates of traumatic events in hoarding cases $(15,24,25)$, rates of comorbid posttraumatic stress disorder (PTSD) among patients reporting hoarding have been equal to or lower than rates for other anxiety disorders in most studies, ranging from 0 $23 \%(13,15,17)$.

Hoarding has been thought to be associated with impulse control problems, particularly those characterized by acquisition such as compulsive buying, kleptomania, and the excessive acquisition of free things $(4,26)$. Frost et al. (26) found that over half of hoarding cases had clinically significant compulsive buying, and when the tendency to excessively acquire free things was included, $86 \%$ had at least moderate acquisition problems. Similarly, Mueller et al. (4) found that nearly two-thirds of hoarding individuals suffered from compulsive buying. To date, however, there are no data on acquisition problems in a large, carefully-diagnosed sample of people with HD. While kleptomania has been reported anecdotally among people with hoarding problems (27) and found to be associated with hoarding behaviors in a nonclinical sample (28), as yet, no data have linked the two clinical conditions. Rates of attention deficit-hyperactivity disorder (ADHD) among hoarding samples have exceeded that of nonclinical groups $(29,30)$ and often exceeding that of people with OCD and other clinical comparison groups $(29,31)$. Tolin and Villavicencio (32) reported that inattentive ADHD symptoms, but not hyperactivity, predicted severity of hoarding after controlling for negative affect.

Hoarding has been associated with a wide variety of personality disorders as well. The most frequent finding has been that hoarding is associated with obsessive compulsive personality disorder (OCPD), and in some cases even when the hoarding criterion is excluded $(5,16,18$, $19,23)$. However, studies using hoarding samples not drawn from OCD patients have failed to find elevated rates of OCPD when the hoarding criterion was excluded $(17,33)$. Other personality disorders have sometimes, but not routinely, been found to be associated with hoarding. 
Reports of gender differences in hoarding comorbidity have been mixed. Labad et al. (34) found no gender differences in hoarding frequency among OCD patients, whereas Wheaton et al. (21) reported greater OCD symptom severity among women with versus without hoarding, although no such differences emerged among men. In contrast, Samuels et al. (23) found higher frequencies of most types of obsessions and several compulsions in men with hoarding-related OCD compared to men with non-hoarding OCD. Among women, only symmetry obsessions and ordering compulsions were more frequent in hoarding than nonhoarding OCD patients. No studies have reported on gender differences in samples recruited for hoarding. Because of the inconsistencies in the findings and the narrow population from which these samples were drawn (OCD patients), no clear hypotheses regarding gender can be made with respect to comorbidity.

The present study employs the largest sample to date of participants solicited solely for hoarding symptoms and using diagnostic criteria for hoarding disorder that match those currently proposed for DSM-5 (1). This study also solicited participants regardless of their interest in treatment and utilized well-validated measures of hoarding and other symptoms. Comorbidity was compared across participants with HD and participants with OCD without hoarding. Based on previous research, we predicted that:

1. A minority of individuals with $\mathrm{HD}$ will be diagnosed with OCD.

2. Major depressive disorder will be the most frequent diagnosis in both groups and significantly more frequent in HD than OCD participants.

3. GAD and social phobia will be diagnosed in HD participants at least as frequently as OCD.

4. Frequency of traumatic events but not PTSD will be greater among HD than OCD participants.

5. Acquisition-related impulse control problems (compulsive buying, excessive acquisition of free things, kleptomania) will be more frequent in HD than OCD participants.

6. Inattentive ADHD, but not hyperactivity, will occur more frequently in HD than OCD participants.

7. OCPD will occur more frequently in HD than OCD, but not when the hoarding criterion is removed.

No gender differences were hypothesized, but exploratory analyses of gender were conducted.

\section{Methods}

\section{Participants}

Hoarding participants with "a large amount of clutter, trouble using rooms in the home, difficulty throwing things away" were recruited from health and mental health clinic settings, newspaper and informational websites, and through investigator media appearances. Given the acknowledged limited insight among people with HD (35), these recruitment strategies were intended to secure a representative sample of HD participants who might not seek treatment. OCD participants were recruited from anxiety and mental health clinic settings, as well as media and advertisements. Mental health clinics were the major referral source (50\%), followed by media and advertisements (41\%) and referrals by family or friends who knew about the study $(9 \%)$. Groups did not differ significantly on referral sources, ChiSq (2) $=2.5, \mathrm{p}=.29$. 
All participants were 18 or older. Consistent with current proposed DSM-5 criteria for hoarding (1), inclusion in the HD group required interviewer ratings of moderate or greater clutter, difficulty discarding, and either distress or impairment from hoarding on the Hoarding Rating Scale Interview. In addition, the clutter and difficulty discarding could not be attributed to another OCD symptom (e.g., contamination, checking). The authors trained the interviewers to administer the HRS-Interview and served as consultants to resolve any diagnostic questions. To study hoarding in the context of other disorders, we did not require HD to be the primary diagnosis and non-hoarding symptoms of OCD were permitted. OCD participants had a DSM-IV diagnosis of OCD (non-hoarding) as their primary (most severe) problem; concurrent hoarding symptoms were required to be below moderate levels (not qualify for HD group) based on the HRS Interview.

Study candidates were excluded if they (a) reported suicidal ideation or other risk factors requiring immediate attention, (b) had current psychotic symptoms, (c) reported substance abuse or dependence within the past 3 months, or (d) showed significant cognitive impairment such as mental retardation or dementia (assessed using the Orientation-MemoryConcentration Test (36)) that could compromise their ability to provide informed consent or complete the assessments. Excluded from the study were 44 people whose symptoms were judged to be subclinical (30 HD and $14 \mathrm{OCD}$ ), 26 for whom OCD was not their primary diagnosis, and 12 with comorbid exclusionary diagnoses (e.g., psychosis, substance abuse, etc.).

The final sample of $313 \mathrm{HD}$ and OCD participants (see Figure 1) was $67.7 \%$ women; $85.6 \%$ identified as white, 7.7\% African American, 2.6\% Asian American, 1.0\% American Indian or Alaska Native, and 2.2\% Hispanic. Of these, 217 met HD criteria (178 without OCD and 39 [18\%] with co-morbid OCD) and 96 met OCD criteria without HD.

Participants' mean age was 47.0 (s.d. $=14$; range $=18-78$ ). HD participants were significantly older (approximately 18 years on average) than the OCD participants (Table 1). Additional analyses were conducted to elucidate the possible impact of these age differences. The groups also differed on gender $\left(\chi^{2}=27.6, p<.001\right)$, with more women in the HD than OCD group (78.7\% vs. $46.9 \%$ ). Consequently, Tarone's $\chi^{2}$ was calculated to determine whether differences between HD and OCD participants varied by gender. There were no differences in education or income between the two groups.

\section{Measures}

The Anxiety Disorders Inventory Schedule for DSM-IV Lifetime version [ADIS-IV-L (37)] was used to diagnose anxiety, mood, somatoform, and substance use disorders. Only current diagnoses were reported here. In addition to diagnoses, adult traumatic events and those in childhood were coded from the ADIS PTSD interview section.

The Structured Clinical Interview for DSM - Axis II Personality Disorders [SCID-II (38)] was administered to participants who endorsed the number of criteria needed for diagnosis minus one on a SCID-II Questionnaire (39).

The Minnesota Impulsive Disorders Inventory [MIDI (40)] modules for compulsive buying, kleptomania, pathological gambling, intermittent explosive disorder, trichotillomania, and pyromania were administered. An additional module for the pathological acquisition of free things was added with questions that paralleled those of the other impulse control disorders. MIDI interviews were missing for 7 participants.

The Hoarding Rating Scale Interview [HRS-I (10)] is a semi-structured interview containing 5 questions covering clutter, difficulty discarding, acquisition, distress, and impairment. A 
reliable and valid measure of hoarding, it discriminates hoarding from non-hoarding respondents with high sensitivity and specificity (10). The HRS-Interviews conducted in the clinic correlate highly $(\mathrm{r}=.91)$ with those administered in the home $(10)$, as well as with other measures of hoarding such as the Saving Inventory - Revised and Clutter Image Rating (10). The HRS-I clinic-home correlation was .91 for a subset of 168 participants from the current study who were assessed in their home in addition to the clinic. The interview items were used to diagnose HD as per proposed DSM-5 criteria (1).

The Saving Inventory - Revised [SI-R (9)] is a widely used 23-item self-report inventory containing 3 subscales: clutter, difficulty discarding, and excessive acquisition; reliability and validity are well established. The typical clinical cutoff for the SI-R total is 41 (8).

The Attention Deficit/Hyperactivity Disorder Symptoms Scale [ADHDSS (41)] is an 18-item self-report checklist of inattention and hyperactivity symptoms. Because the items reflect DSM-IV symptom criteria, we calculated diagnoses of inattention and hyperactivity ADHD to estimate these comorbidities. The ADHDSS was missing for 13 participants.

\section{Procedure}

The present 2-site study was approved by the Institutional Review Boards at Smith College, Boston University, and Hartford Hospital. All participants signed an informed consent form prior to the start of the study at either Boston University or The Institute of Living/Hartford Hospital. Clinical interviews were conducted by master's level clinical psychologists or postdoctoral fellows trained to criteria using the ADIS-IV-L and supervised by licensed psychologists. Participants who met diagnostic criteria completed the self-report forms.

\section{Results}

\section{Hoarding Severity}

$t$-tests conducted on SI-R scores indicated that, as expected, the HD group had significantly higher scores than did the OCD group on each subscale as well as the total score (see Table 1). The mean SI-R total score of the HD group was comparable to other studies involving clinically significant hoarding cases (9) and well above the clinical cutoff (8).

\section{Frequency of OCD in Hoarding Disorder}

Among the 217 HD participants, only 39 (18.0\%) met criteria for OCD, although this varied by gender. Only $15.0 \%$ (25/167) of women with HD met criteria for OCD, whereas $28.0 \%$ (14/50) of men did so $\left(\chi^{2}=4.43, p=.035\right)$.

\section{Axis I Diagnoses: Frequency and Comparisons of HD versus OCD by Gender}

Table 2 presents comparisons of the frequency of diagnoses and odds ratios for HD and OCD participants by gender. As predicted, MDD was the most common diagnosis among HD participants, occurring in $50.7 \%$ of the sample, and was more frequent in HD than OCD participants. The frequency did not differ by gender. No other mood disorder was significantly related to group status.

Because the younger age of the OCD group may mean they had less opportunity to develop MDD, we conducted additional analyses. First, there was no age difference between participants with or without an MDD diagnosis, $t(311)=1.03, p>.05$, as would have been expected if sample differences were accounted for by age. Second, the MDD frequencies in HD participants exceeded the OCD group frequencies in each decade of life (ages 21-30: 42.9 vs. $21.9 \%$; $31-40: 53.8$ vs. $47.4 \%$; $41-50: 64.3$ vs. $46.2 \%$; >50: 45.3 vs $29.4 \%$ ). Furthermore, the frequency of MDD among the oldest group of HD participants ( $\mathrm{n}=139$ over 
age 50) was lower than the frequency found among the younger 41-50 year old age cohort $\left(\mathrm{n}=56 ; X^{2}=5.75, p=.017\right)$.

Social phobia (23.5\%) and GAD (24.4\%) were the most frequently diagnosed anxiety disorders among HD participants; no one in the HD group was diagnosed with panic disorder. Overall, HD and OCD participants did not differ in the frequency of any specific anxiety disorder other than panic disorder. With regard to gender differences across the clinical samples, however, men with HD were more likely to be diagnosed with social phobia than were men with OCD ( 28.0 vs. $\left.11.8 \% ; \chi^{2}=4.19, p=.041\right)$, but no such difference emerged among the women ( 22.2 vs. $28.9 \% ; \chi^{2}=0.89, p>.05$ ). This difference appears to be due to the lower frequency of social phobia among men with OCD. Within the HD sample, men and women with HD did not differ in the frequency of social phobia $\left(\chi^{2}=0.73, p>.05\right)$.

As expected, HD and OCD participants did not differ in the frequency of PTSD diagnoses, whereas HD participants were significantly more likely to have experienced a traumatic event than OCD participants ( 49.8 vs. $\left.24.4 \% ; \chi^{2}=16.1, p<.001\right)$, as well as more likely to have experienced a trauma during childhood ( 32.8 vs. $20.9 \% ; \chi^{2}=4.1, p<=.042$ ).

HD participants were no more likely than were OCD participants to have a comorbid anxiety disorder, and no more likely to have an anxiety and/or mood disorder.

Table 3 displays current comorbidities for MIDI impulse control disorders by gender. As expected, HD participants were more likely than OCD participants to be diagnosed with acquisition-related impulse control problems, specifically compulsive buying, acquiring free things, and kleptomania. Although the odds ratios for MIDI acquisition disorders appeared greater for men than women, none of these relationships varied significantly by gender. However, more women than men met criteria for compulsive buying for both groups combined $\left(55.3 \%\right.$ vs. $\left.27.0 \%, \chi^{2}=21.8, p<.001\right)$, and for HD participants (64.8\% vs. $48.0 \%$; $\left.\chi^{2}=4.54, p=.033\right)$. Overall, $78.3 \%(166 / 212)$ of HD participants met criteria for one or more acquisition-related impulse control problems (buying, free things, kleptomania); $40.1 \%$ $(85 / 212)$ met criteria for two such problems, and 6.1\% (13/212) met criteria for all three. However, HD participants did not display a higher frequency of any other impulse control disorder than did OCD participants.

HD participants were significantly more likely than OCD participants to meet criteria for the inattentive subtype of ADHD (see Table 3). This difference did not vary by gender. As expected, there was no difference between HD and OCD participants in the frequency of hyperactivity, although Cochran's $\chi^{2}$ approached significance ( $p=.051$ ), with HD participants more frequently having this subtype. This also did not vary by gender.

\section{Personality Disorders in HD and OCD Participants}

The frequency of OCPD differed significantly by group, diagnosed in $29.5 \%$ of HD participants and $16.7 \%$ of OCD participants $\left(\chi^{2}=4.85 . p=.028\right)$. However, as hypothesized, when hoarding was removed from the criteria, the two groups did not differ (18.4\% vs. $\left.14.6 \%, \chi^{2}=0.40, p>.05\right)$. Only 2 other personality disorders had frequencies greater than $4 \%$. Avoidant personality disorder was diagnosed in $8.8 \%$ of HD and $6.2 \%$ of OCD participants $\left(\chi^{2}=0.14, p>.05\right)$, and borderline personality disorder was diagnosed in $5.4 \%$ of $\mathrm{HD}$ and $3.3 \%$ of OCD participants $\left(\chi^{2}=0.54, p>.05\right)$. A comparison across groups on the presence of any personality disorder was not significant $\left(\chi^{2}=0.15, p>.05\right)$. No differences by gender occurred in any personality disorder analyses. 


\section{Comparison of HD Participants with and without OCD}

A comparison of HD participants with and without OCD revealed few significant differences. There were no differences in severity of hoarding on the HRS-I $(\mathrm{t}(216)=-0.33$, $p>.05$, or on the SI-R total, $\mathrm{t}(198)=0.96, p>.05$. However, the HD plus OCD group had a higher proportion of men than did the HD only group (36 vs. $20 \%$; Chi Sq $=4.43, \mathrm{p}=.035$ ). The only other difference was a higher frequency of pyromania in the HD plus OCD group than the HD only group (6.3 vs $0.0 \%$; Chi Sq with continuity correction $=5.0, \mathrm{p}=.025$ ). However, given the small number of cases ( 2 vs. 1) and the large number of comparisons made, this difference should be viewed cautiously.

\section{Discussion}

As expected, relatively few HD participants $(<20 \%)$ were diagnosed with OCD. In fact, several other disorders (MDD, GAD, social phobia) were more frequent among HD than OCD cases. This finding accords with recent research suggesting that hoarding is not a subtype of OCD, but instead a distinct condition related to a variety of disorders (1). Furthermore, the low rate of OCD in HD argues that studies of hoarding that recruit from OCD clinics will not represent the majority of people with hoarding disorder. It should be noted, however, that the rate of OCD in hoarding (18\%) is considerably greater than in the general population (1-2\%), which suggests that although hoarding may be distinct from OCD, it is still related to it.

Men with HD were diagnosed with OCD nearly twice as often as women. Because there were few men in the current sample, and the possibility that HD is more frequent in men than women (5), some caution is warranted with respect to this finding. Nevertheless, this gender difference deserves further scrutiny.

There were no differences between HD participants with and without OCD in the severity of hoarding symptoms, and the comorbidity pattern was similar. The higher frequency of men with both disorders deserves further study.

As hypothesized, MDD was the most frequent comorbid condition among HD patients, with more than half the sample receiving that diagnosis. Further, MDD was significantly more common in the HD than the OCD group, and age differences between groups did not appear to account for this finding. Although less frequent, GAD and social phobia were diagnosed in about one quarter of HD cases, similar to rates in the OCD sample. Accordingly, it is not surprising that the frequency of these disorders fall well within the ranges reported for HD participants recruited from both OCD and independent hoarding samples in previous research. Although men with HD were diagnosed with social phobia more frequently than women with HD ( 28 vs. $22 \%$ ), the significant interaction between group and gender appears to be due to the much lower frequency of social phobia in men versus women with OCD (11 vs. $22 \%$ ). Whether social phobia plays a role in the apparent social isolation and low marriage rate of many people who hoard (13) merits attention in future research.

As predicted, the overall rate of PTSD was not higher in HD, but HD participants were more likely to have experienced any traumatic event as well as a traumatic event in childhood than were OCD participants. These findings are consistent with the reports of more frequent traumatic life events among people with OCD who hoard (5, 21, 24), and with Landau et al.'s (15) finding of elevated traumatic life events among people recruited for hoarding. Nearly $50 \%$ of HD participants reported experiencing a traumatic event. Whether this was due to a lower threshold for defining trauma or an actual difference in life experience is not clear. If the latter, perhaps possessions buffer the development of full blown PTSD, 
consistent with reports by people who hoard that possessions are sources of comfort and security (2).

As anticipated, more HD than OCD participants met criteria for compulsive buying, excessive acquisition of free things, and kleptomania. This is consistent with recent findings that well over $80 \%$ of people with self-reported hoarding problems acquire excessively (26). These may not be comorbidities, but rather part of the hoarding phenotype itself. However, at present, excessive acquisition is not included among required criteria for diagnosing HD (1). Nonetheless, these acquisition-related impulse control problems must be addressed during treatment. While the odds ratio of MIDI acquisition disorders (especially compulsive buying) appeared greater for men than women, there were no gender effects. The lower odds ratio in women may need further exploration, but may be due partly to the fact that compulsive buying was relatively common for women with OCD $(21 \%)$ compared to men with OCD (6\%). Compulsive acquisition has been found to be associated with OCD symptoms in largely female samples (26). Perhaps it is less so for males. This is the first investigation to find elevated levels of kleptomania among people who hoard. With a base rate of nearly $10 \%$, assessing kleptomania and stealing in HD clients is important for developing an effective treatment plan that prioritizes reduction of this dangerous behavior. Previous research has suggested an association between hoarding and pathological gambling (42). The absence of a difference in this study may be due to the use of a clinical (OCD) rather than a nonclinical comparison group since OCD has also been found to be associated with increased pathological gambling (42).

Overall axis I comorbidity was high among HD participants as nearly $75 \%$ had a mood and/ or anxiety disorder, although this rate did not differ from that for OCD participants. The high frequency of these conditions raises questions about the role of anxiety and depression in HD. Do they result from the significant burden and impairment produced by hoarding behavior (6)? Or do anxiety disorders and depression predate hoarding and play a role in its development? Examination of the timing of the onset of HD versus comorbid conditions was beyond the scope of this paper, but is important for understanding the determinants of hoarding.

Consistent with our hypothesis, inattentive ADHD was significantly more frequent in HD than in OCD, evident in nearly $30 \%$ of HD participants. Attention problems have been hypothesized to be among information processing deficits that may underlie hoarding (2), but these findings make it clear that, although frequent, attention deficit is not a universal characteristic.

As hypothesized, OCPD was more frequent in HD than OCD, but when hoarding was omitted from the criteria for OCPD, samples did not differ. Overall, there were no differences between the HD and OCD groups on frequency of any other personality disorders. However, even when hoarding was removed as a criterion, OCPD was the personality disorder most characteristic of HD, occurring more than twice as often as the next most common PD.

There are several limitations to this study. As for much of the research on hoarding, many more women than men participated in the HD group, a difference not evident in the OCD group. The small number of HD men contrasts sharply with epidemiological findings suggesting that hoarding is more common among men than women in the general population $(3,5)$. Perhaps the slightly higher rate of social phobia among men with HD explains why they don't volunteer to participate in research studies. A second limitation was that the HD group was significantly older than the OCD group. This is also characteristic of much of the research on participants solicited for hoarding. Nevertheless, the difference may have 
influenced some comparisons in this study. Additional research clarifying age of onset of these comorbidities will help determine whether the age difference played a role in the findings. Also, although there was no difference between groups on referral sources, it is possible the separate recruitment of HD and OCD participants introduced some bias that may have influenced the findings. Finally, our measures of ADHD relied on self-report rather than information gained from a diagnostic interview.

\section{Acknowledgments}

This research was funded by grants from NIMH to Randy Frost (R01 MH068008) and Gail Steketee (R01 MH068007).

Drs. Frost and Steketee receive royalties from sales of books related to hoarding and its treatment.

Dr. Tolin has received research funding from Organon/Merck, Endo Pharmaceuticals, and Eli Lilly and Company.

\section{References}

1. Mataix-Cols D, Frost RO, Pertusa A, Clark LA, Saxena S, Leckman JF, et al. Hoarding disorder: a new diagnosis for DSM-V? Depress Anxiety. 2010 Jun; 27(6):556-572. [PubMed: 20336805]

2. Frost RO, Hartl TL. A cognitive-behavioral model of compulsive hoarding. Behaviour Research and Therapy. 1996 Apr; 34(4):341-350. [PubMed: 8871366]

3. Iervolino AC, Perroud N, Fullana MA, Guipponi M, Cherkas L, Collier DA, et al. Prevalence and heritability of compulsive hoarding: a twin study. Am J Psychiatry. 2009 Oct; 166(10):1156-1161. [PubMed: 19687130]

4. Mueller A, Mitchell JE, Crosby RD, Glaesmer H, de Zwaan M. The prevalence of compulsive hoarding and its association with compulsive buying in a German population-based sample. Behav Res Ther. 2009 Aug; 47(8):705-709. [PubMed: 19457476]

5. Samuels JF, Bienvenu OJ, Grados MA, Cullen B, Riddle MA, Liang KY, et al. Prevalence and correlates of hoarding behavior in a community-based sample. Behav Res Ther. 2008 Jul; 46(7): 836-844. [PubMed: 18495084]

6. Tolin DF, Frost RO, Steketee G, Gray KD, Fitch KE. The economic and social burden of compulsive hoarding. Psychiat Res. 2008; 160:200-211.

7. Pertusa A, Frost RO, Fullana MA, Samuels J, Steketee G, Tolin D, et al. Refining the diagnostic boundaries of compulsive hoarding: a critical review. Clin Psychol Rev. 2010 Jun; 30(4):371-386. [PubMed: 20189280]

8. Frost RO, Hristova V. Assessment of hoarding. J Clin Psychol. 2011 Feb 23.

9. Frost RO, Steketee G, Grisham J. Measurement of compulsive hoarding: Saving Inventory-Revised. Behaviour Research and Therapy. 2004 Oct; 42(10):1163-1182. [PubMed: 15350856]

10. Tolin DF, Frost RO, Steketee G. A brief interview for assessing compulsive hoarding: the Hoarding Rating Scale-Interview. Psychiatry Res. 2010 Jun 30; 178(1):147-152. [PubMed: 20452042]

11. Hasler G, LaSalle-Ricci VH, Ronquillo JG, Crawley SA, Cochran LW, Kazuba D, et al. Obsessive-compulsive disorder symptom dimensions show specific relationships to psychiatric comorbidity. Psychiatry Res. 2005 Jun 15; 135(2):121-132. [PubMed: 15893825]

12. LaSalle-Ricci VH, Arnkoff DB, Glass CR, Crawley SA, Ronquillo JG, Murphy DL. The hoarding dimension of OCD: psychological comorbidity and the five-factor personality model. Behav Res Ther. 2006 Oct; 44(10):1503-1512. [PubMed: 16386705]

13. Ayers CR, Saxena S, Golshan S, Wetherell JL. Age at onset and clinical features of late life compulsive hoarding. Int J Geriatr Psychiatry. 2010 Feb; 25(2):142-149. [PubMed: 19548272]

14. Fontenelle LF, Mendlowicz MV, Soares ID, Viersiani M. Patients with obsessive-compulsive disorder and hoarding symptoms: A distinct clinical subtype? Comprehensive Psychiatry. 2004; 45:375-383. [PubMed: 15332201] 
15. Landau D, Iervolino AC, Pertusa A, Santo S, Singh S, Mataix-Cols D. Stressful life events and material deprivation in hoarding disorder. J Anxiety Disord. 2011 Mar; 25(2):192-202. [PubMed: 20934847]

16. Lochner C, Kinnear CJ, Hemmings SM, Seller C, Niehaus DJ, Knowles JA, et al. Hoarding in obsessive-compulsive disorder: clinical and genetic correlates. Journal of Clinical Psychiatry. 2005 Sep.66:1155-1160. [PubMed: 16187774]

17. Pertusa A, Fullana MA, Singh S, Alonso P, Menchon JM, Mataix-Cols D. Compulsive hoarding: OCD symptom, distinct clinical syndrome, or both? Am J Psychiatry. 2008 Oct; 165(10):12891298. [PubMed: 18483134]

18. Samuels JF, Bienvenu OJ, Riddle MA, Cullen BA, Grados MA, Liang KY, et al. Hoarding in obsessive compulsive disorder: results from a case-control study. Behav Res Ther. 2002 May; 40(5):517-528. [PubMed: 12043707]

19. Samuels JF, Bienvenu OJ, Pinto A, Fyer AJ, McCracken JT, Rauch SL, et al. Hoarding in obsessive-compulsive disorder: Results from the OCD Collaborative Genetics Study. Behaviour Research and Therapy. 2007 Jul 3.45:673-686. [PubMed: 16824483]

20. Steketee G, Frost RO, Tolin DF, Rasmussen J, Brown TA. Waitlist-controlled trial of cognitive behavior therapy for hoarding disorder. Depress Anxiety. 2010 May; 27(5):476-484. [PubMed: 20336804]

21. Wheaton M, Timpano KR, Lasalle-Ricci VH, Murphy D. Characterizing the hoarding phenotype in individuals with OCD: associations with comorbidity, severity and gender. J Anxiety Disord. 2008; 22(2):243-252. [PubMed: 17339096]

22. Tolin DF, Meunier SA, Frost RO, Steketee G. Hoarding among patients seeking treatment for anxiety disorders. J Anxiety Disord. 2011 Aug 10.25:43-48. [PubMed: 20800427]

23. Samuels JF, Bienvenu OJ, Pinto A, Murphy DL, Piacentini J, Rauch SL, et al. Sex-specific clinical correlates of hoarding in obsessive-compulsive disorder. Behav Res Ther. 2008 Sep; 46(9):10401046. [PubMed: 18692168]

24. Cromer KR, Schmidt NB, Murphy DL. Do traumatic events influence the clinical expression of compulsive hoarding? Behav Res Ther. 2007 Nov; 45(11):2581-2592. [PubMed: 17673166]

25. Tolin DF, Meunier SA, Frost RO, Steketee G. Course of compulsive hoarding and its relationship to life events. Depress Anxiety. 2010 Sep; 27(9):829-838. [PubMed: 20336803]

26. Frost RO, Tolin DF, Steketee G, Fitch KE, Selbo-Bruns A. Excessive acquisition in hoarding. J Anxiety Disord. 2009 Jun; 23(5):632-639. [PubMed: 19261435]

27. Frost, RO.; Steketee, G. Stuff: Compulsive hoarding and the meaning of things. New York: Houghton-Mifflin-Harcourt; 2010.

28. Hayward LC, Coles ME. Elucidating the relation of hoarding to obsessive compulsive and impulse control disorders. Journal of Psychopathology and Behavioral Assessment. 2009; 31:220-227.

29. Grisham JR, Brown TA, Savage CR, Steketee G, Barlow DH. Neuropsychological impairment associated with compulsive hoarding. Behav Res Ther. 2007 Jan 12.45:1471-1483. [PubMed: 17341416]

30. Grisham JR, Norberg MM, Williams AD, Certoma SP, Kadib R. Categorization and cognitive deficits in compulsive hoarding. Behav Res Ther. 2010 Sep; 48(9):866-872. [PubMed: 20542489]

31. Sheppard B, Chavira D, Azzam A, Grados MA, Umana P, Garrido H, et al. ADHD prevalence and association with hoarding behaviors in childhood-onset OCD. Depress Anxiety. 2010 Jul; 27(7): 667-674. [PubMed: 20583294]

32. Tolin DF, Villavicencio A. Inattention, but not OCD, predicts the core features of hoarding disorder. Behaviour Research and Therapy. 2011; 49:120-125. [PubMed: 21193171]

33. Frost RO, Steketee G, Williams LF, Warren R. Mood, personality disorder symptoms and disability in obsessive compulsive hoarders: a comparison with clinical and nonclinical controls. Behaviour Research and Therapy. 2000 Nov.38:1071-1081. [PubMed: 11060936]

34. Labad J, Menchon JM, Alonso P, Segalas C, Jimenez S, Jaurrieta N, et al. Gender differences in obsessive-compulsive symptom dimensions. Depress Anxiety. 2008; 25(10):832-838. [PubMed: 17436312]

35. Tolin DF, Fitch KE, Frost RO, Steketee G. Family informants' perceptions of insight in compulsive hoarding. Cognitive Therapy and Research. 2010; 34:69-81. 
36. Katzman R, Brown T, Fuld P, Peck A, Schechter R, Schimmel H. Validation of a short Orientation-Memory-Concentration Test of cognitive impairment. Am J Psychiatry. 1983 Jun; 140(6):734-739. [PubMed: 6846631]

37. Brown, TA.; DiNardo, PA.; Barlow, DH. Anxiety Disorders Interview Schedule for DSM-IV. San Antonio, TX: The Psychological Corporation; 1994.

38. First, MB.; Spitzer, RL.; Gibbon, M.; Williams, JBW. Structured Clinical Interview for DSM-IV Personality Disorders, (SCID-II). Washington, D.C: American Psychiatric Press, Inc.; 1997.

39. Ullrich S, Deasy D, Smith J, Johnson B, Clarke M, Broughton N, et al. Detecting personality disorders in the prison population of England and Wales: Comparing case identification using the SCID-II screen and the SCID-II clinical interview. Journal of Forensic Psychiatry \& Psychology. 2008; 19:301-322.

40. Christenson GA, Faber RJ, de Zwaan M, Raymond NC, Specker SM, Ekern MD, et al. Compulsive buying: descriptive characteristics and psychiatric comorbidity. J Clin Psychiatry. 1994 Jan; 55(1): 5-11. [PubMed: 8294395]

41. Barkley, RA.; Murphy, KR. Attention-Deficit Hyperactivity Disorder: A clinical workbook. 2nd ed.. New York: Guilford Press; 1998.

42. Frost RO, Meagher BM, Riskind JH. Obsessive-compulsive features in pathological lottery and scratch ticket gamblers. Journal of Gambling Studies. 2001; 17:5-19. [PubMed: 11705017]

43. Agresti A. A survey of exact inference for contingency tables. Statistical Science. 1992; 7:131177. 


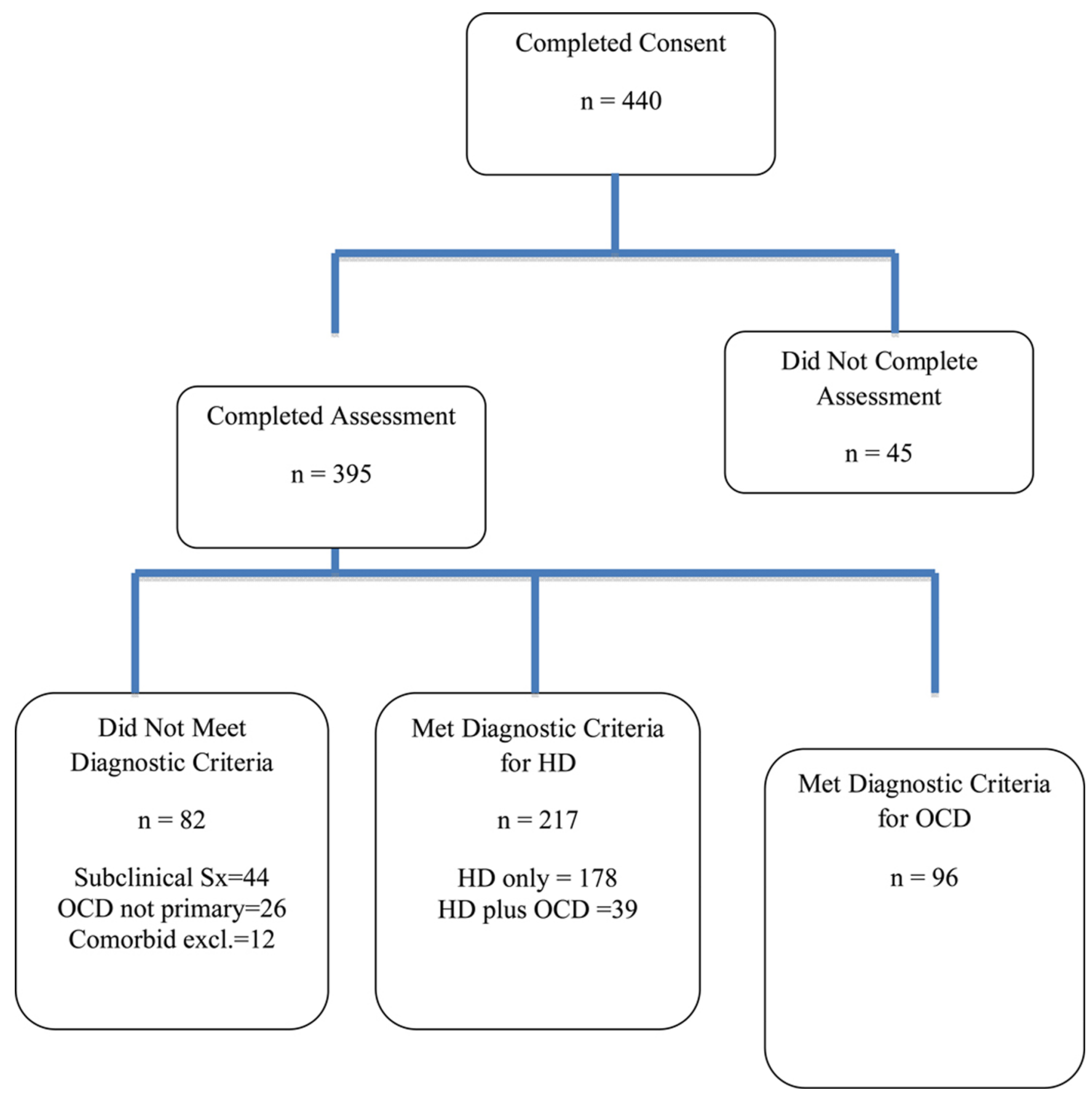

Figure 1.

Flowchart of participants 


\section{Table 1}

Comparisons between HD and OCD participants on demographics and hoarding severity.

\begin{tabular}{|l|c|c|c|c|}
\hline & HD & OCD & $\mathbf{t}$ & $\boldsymbol{p}$ \\
\hline Age & $\begin{array}{c}52.63(10.3) \\
\text { range 19-78 }\end{array}$ & $\begin{array}{c}34.56(13.6) \\
\text { range 18-74 }\end{array}$ & 12.95 & .001 \\
\hline Gender & $78.7 \%$ female & $46.9 \%$ female & $\chi^{2}=27.6$ & .001 \\
\hline Education & $3.91(1.4)$ & $4.20(1.3)$ & 1.70 & .09 \\
\hline Income & $4.39(2.7)$ & $3.87(2.7)$ & 1.46 & .15 \\
\hline Saving Inventory Revised Total (SIR) & $\begin{array}{c}62.0(13.7) \\
\text { range 21-92 }\end{array}$ & $\begin{array}{c}16.1(15.3) \\
\text { range 0-65 }\end{array}$ & 25.87 & .001 \\
\hline SIR - Clutter & $\begin{array}{c}26.4(6.1) \\
\text { range 5-36 }\end{array}$ & $\begin{array}{c}4.8(6.5) \\
\text { range 0-29 }\end{array}$ & 27.60 & .001 \\
\hline SIR - Difficulty Discarding & $\begin{array}{c}19.6(4.8) \\
\text { range 3-28 }\end{array}$ & $\begin{array}{c}6.4(6.2) \\
\text { range 0-25 }\end{array}$ & 20.08 & .001 \\
\hline SIR - Excessive Acquisition & $\begin{array}{c}15.9(5.8) \\
\text { range 2-28 }\end{array}$ & $\begin{array}{c}4.9(5.4) \\
\text { range 0-27 }\end{array}$ & 15.49 & .001 \\
\hline
\end{tabular}

Note: Education levels were based on an 8-point scale ranging from 1=PhD, MD or equivalent to 8=Grammar school. Level 3 was "some graduate school" and 4 was "BA, BS or equivalent". Income levels were also based on an 8-point scale ranging from $1=" \$ 70,000$ and up" to $8=" \$ 10,000$ or less". Level 3 was " $\$ 50,001-60,000 "$ and 4 was “ $\$ 40,001-50,000)$ 


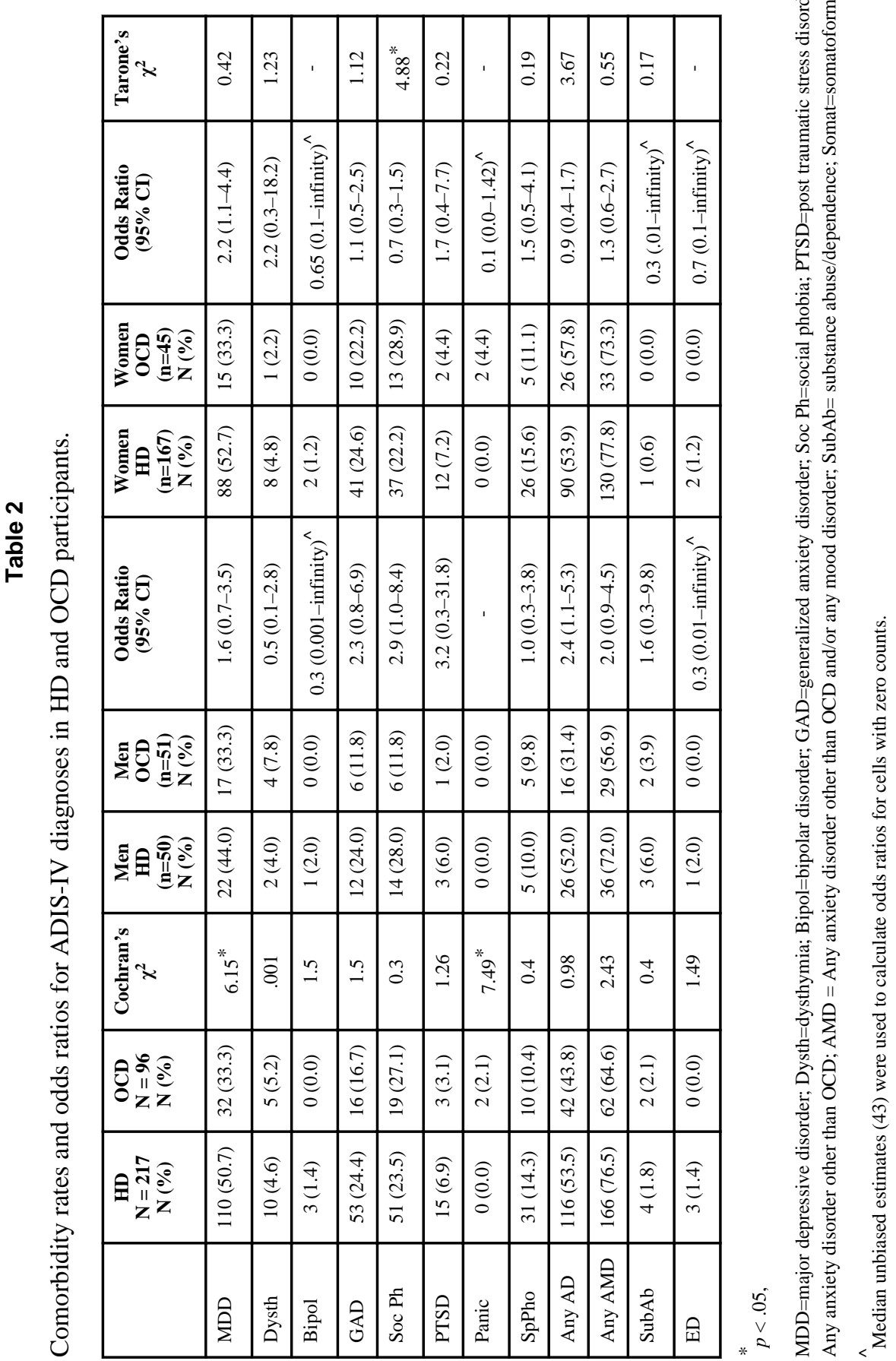


